\title{
ESPIRITO UCHINANCHU OKINAWANOS EM SÃO PAULO
}

\author{
Sônia Maria de Freitas*
}

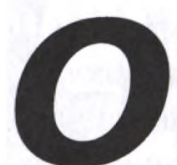

presente texto ${ }^{1}$ aborda a imigração okinawana ${ }^{2}$, dentro da história do processo imigratório em São Paulo. São aqui apresentadas as peculiaridades e as especificidades dessa imigração, bem como a saga dos imigrantes de Okinawa em São Paulo: sua origem, a viagem, destino, trabalho no campo e na cidade, lazer, religião, cultura e preconceitos e a reconstrução da identidade étnica para os descendentes da primeira e da segunda gerações ${ }^{3}$.

Iniciada em 1908, a imigração japonesa foi inicialmente subvencionada pelo governo brasileiro e, mais tarde, pelo governo japonês. $\mathrm{Na}$ longa viagem de 50 a 60 dias, muitos imigrantes faleceram por causa das péssimas condições sanitárias nos navios. Os imigrantes das primeiras décadas vieram trabalhar na lavoura de café e foram distribuídos nas regiões próximas às estradas de ferro Mogiana, Paulista, Noroeste, entre outras. Houve experiências de diversas colônias agrícolas por grupos particulares e por companhias de colonização japonesas que adquiriram terras ou as receberam em concessão.

Entre as 47 províncias japonesas, Okinawa foi a que contribuiu com o maior número de imigrantes para São Paulo: $12 \%$ do total.

Segundo dados fornecidos pelo Consulado Geral do Japão, de 1908 a 1986, entraram mais de 255.580 japoneses no Brasil. A cidade de São Paulo tornou-se a maior cidade japonesa fora do Japão. Estima-se que hoje, a colônia japonesa no Brasil, incluindo os okinawanos e seus descendentes, forme um contingente de cerca 1,35 milhão de pessoas.

Shosei Miyagui (1998, p. 44) afirma que 270 mil okinawanos vivem fora do Japão:

“O Brasil é o que abriga o maior número com 120 mil pessoas, seguido dos Estados Unidos (inclusive ilhas Hawai) com 65 mil. Seguem-se o Peru, com 42 mil pessoas e a Argentina com 30 mil, além de Canadá com 1.200 pessoas e México com 700 pessoas".

$\mathrm{O}$ primeiro grupo de imigrantes japoneses chegou ao Brasil a bordo do Kasato Maru, desembarcando no porto de Santos (SP), no dia 16 de junho de 1908:

"Dos 781 japoneses que formavam esse contingente pioneiro, 325 - ou $41,6 \%$ - eram naturais de Okinawa. Eles partiram do porto de Kobe e chegaram ao porto de Santos após uma longa viagem de 51 dias".(idem)

O escritor e jornalista José Yamashiro (1996, p.31) afirma que "quase todos os okinawanos do Kasato Maru fugiram das fazendas nas quais haviam sido colocados. A maioria deles se concentrou em Santos, onde se formou a primeira, embora pequena, colônia okinawana do Brasil".

É muito difícil precisar o número de entrada de okinawanos no Brasil, pois nas listas de bordo e nos registros da Hospedaria não consta a origem dos imigrantes. A partir de 1913, foi proibida a entrada de imigrantes de Okinawa e de Kagoshima no Brasil. Alegavam que os okinawanos não cumpriam seus contratos e fugiam das fazendas, criavam desavenças com os administradores, tinham o hábito de andarem nus, falavam em dialeto e as mulheres casadas tinham as mãos tatuadas, o 'Hajitchi', como se fosse a aliança para o ocidental. Essa proibição foi suspensa em 1916, em virtude da diminuição de entrada de imigrantes europeus em consequiência da Primeira Guerra Mundial. A imigração okinawana foi novamente proibida em 1920, sendo retomada a partir de 1926 devido a um movimento organizado pelos okinawanos no Brasil. Dessa mobilização surgiu a 'Kyûyô-Kyôkai' (Uchiyama, 1991, p. 144/145). Das fazendas de café fugiam para a Argentina, através da ferrovia, a qual muitos percorriam andando, ou retornavam a Santos com o objetivo de voltar para o Japão.

Ouvimos imigrantes vindos após a Segunda Guerra Mundial, e no início da década de 1950. Entretanto, a maioria dos imigrantes entrevistados chegou ao Brasil no final dos anos 20 e início da década de 1930.

As décadas de maior incidência de nascimento dos nossos informantes foram as de 1910,1920 e 1930 . O maior número de chegadas ocorreu nas décadas de 1930 e 1950 .

Ao aportarem no Brasil, após o desembarque em Santos, esses imigrantes eram levados para a Hospedaria de Imigrantes, na capital paulista. $\mathrm{O}$ okinawano Ruikiti Yasmashiro, que após 57 dias de viagem, de Kobe a Santos, desembarcou em 29 de abril de 1912, relatou a sua permanência nesse local:

"Chegando à Hospedaria de Imigrantes de São Paulo, às 22 horas, fomos imediatamente jantar. Os okinawanos, enjoados da péssima comida de bordo durante a longa viagem, acharam aquela servida na hospedaria muito gostosa. (...) Eu e 


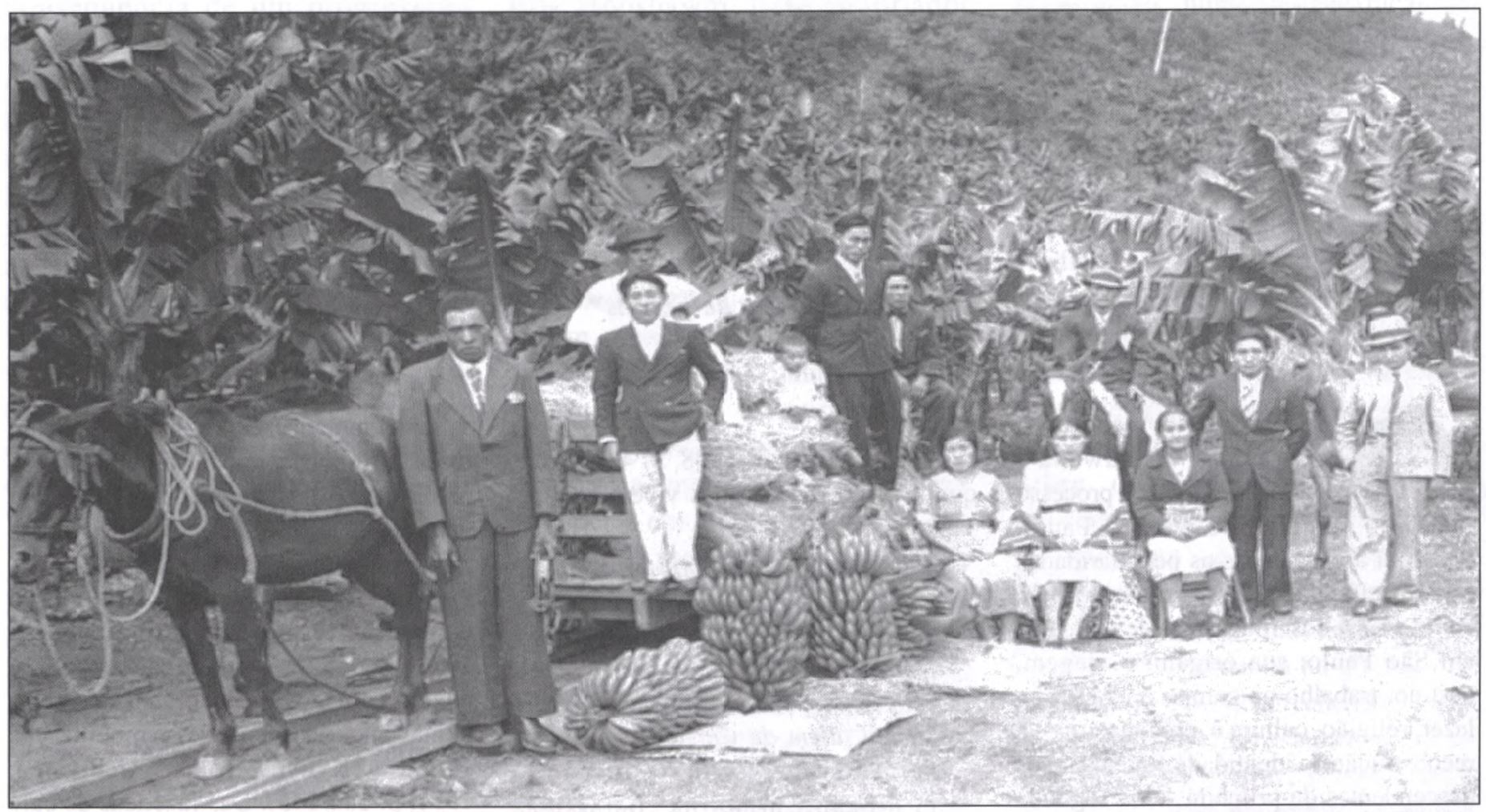

Plantação de bananas de Seian Hanashiro, familiares e empregados de seu sítio; Itariri/SP, 1929.

Foto: Coleção da família Hanashiro

imigrantes de outras províncias reclamamos dos pratos gordurosos. Dormimos pela primeira vez na vida numa cama. (No Japão estávamos acostumados a dormir sobre tatame). Não havia nada para cobrir o corpo. Retiramos um cobertor fino da bagagem de mão. Era fria a noite de maio em São Paulo. Passei a noite acordado. Até hoje me lembro da longa espera pelo amanhecer. [...]" (Yamashiro, 1996, p. 27-28).

Da Hospedaria eram conduzidos para as fazendas do interior. Uma vez instalados nas casas cedidas pelos fazendeiros, pela manhã, ao toque do sino, era hora de começar o trabalho na colheita de café. Pano, peneira e escadinha eram os seus principais instrumentos de trabalho.

O choque cultural pela diferença de costumes causou estranhezas e situações cômicas entre imigrantes de diferentes origens:

“[..] o estranho vestuário usado pelos okinawanos deve ter causado impressão nada lisonjeira nos colonos europeus. Havia homem vestindo só uma ceroula; mulher com camisa masculina e saia sem peças íntimas. "Tias" espanholas teriam aberto as saias para mostrar as calcinhas às japonesas. [...] Depois de um dia de trabalho, os okinawanos tomavam banho e ficavam à vontade como em sua terra de origem: de 'yukata' (quimono leve que se usa depois do banho) ou 'nemaki' (quimono de dormir) ou ainda com uma espécie de pijama curto de Okinawa. E apareciam sem nenhum acanhamento diante dos gaijin (estrangeiros, forasteiros)". (Yamashiro, 1996, 28-29).

\section{TRABALHO NO CAMPO E NA CIDADE}

A maioria dos informantes (35 pessoas) teve o campo como destino e se distribuiu entre os municípios de Capem e Campo Grande (MT), Bauru, Aliança, Presidente Prudente, Araçatuba, Miracatu, Paraguaçu Paulista, Linha Santos-Juquiá (Itariri, Ana Dias, Juquiá), entre outros. Os que tiveram a cidade como primeiro destino (15 pessoas) se dirigiram sobretudo para os municípios de Santo André, São Caetano, Campinas,
Santos, Lins e na capital paulista. Uma parte significativa (31 pessoas) se dedicou à lavoura/agricultura como primeira atividade, e como última profissão predominou a de comerciante (10), agricultor (5), e feirante (5), entre outras. Identificamos mais de 45 diferentes atividades exercidas pelos descendentes, mas a profissão predominante dos descendentes foi a mesma de seus pais: comerciante (42), agricultor (10) e feirante (8).

Outros, trabalharam na construção das estradas de ferro Noroeste, Sorocabana e da que ligava Campo Grande a Bolívia. Esses imigrantes acabaram se instalando na cidade de Campo Grande. Nessa cidade também se encontravam okinawanos vindos do Peru, que cruzaram os Andes em lombo de burro. Inicialmente, dedicaram-se ao cultivo do arroz e do café e, a partir da década de 1920, à horticultura, que se desenvolveu no cinturão verde de hoje. Alguns imigrantes arrendaram terras para plantar arroz e, em 1938, fundaram a Cooperativa Agrícola de Campo Grande.

No caso do estado de São Paulo, boa parte dos okinawanos teve como destino 
a lavoura de café. Na região da Noroeste, foram, entre outras, para a fazenda Aliança situada nas proximidades da cidade de Lins. Nessa fazenda encontravam-se também imigrantes de outras regiões e cidades do Japão, como Tóquio, Osaka, Kiryu.

Em várias cidades do interior do estado, como Pompéia, Bastos, Tupã, Marília, Osvaldo Cruz, Lucélia, Presidente Prudente, os okinawanos tornaram-se pequenos produtores de algodão, amendoim e arroz. Abriram pequenos estabelecimentos comerciais como bares, pastelarias, restaurantes, armazéns, bazares, além de trabalharem em feiras livres.

$\mathrm{Na}$ capital formaram os "cinturões verdes', plantando hortaliças, legumes e frutas contribuindo para o abastecimento da cidade; atuaram também - e ainda atuam - como comerciantes de frutas e legumes, de pastéis e de flores, nas feiras livres ou em grandes mercados.

\section{NA LINHA SANTOS-JUQUIÁ}

Em Santos muitos se tornaram estivadores, carregando, durante dez horas de trabalho, sacas de 60 quilos de café - peso superior ao físico de muitos deles - a 60 réis a saca. Entretanto, a maioria dedicou-se à horticultura nos bairros de Campo Grande, Macuco e Ponta da Praia. Alguns imigrantes foram construir a estrada de ferro Santos-Juquiá. Ao longo da ferrovia, no Vale do Ribeira, foram criando vários pólos agrícolas.

Muitos imigrantes de Okinawa fixaram-se ao longo da linha férrea Santos-Juquiá, entre as décadas de 1910 e 1930. A estrada de ferro foi inaugurada em 1914, pela Southern São Paulo Railway, para a qual muitos deles haviam trabalhado. Na verdade, ela foi construída entre 1911 e 1920 . O projeto original era ligar Santos a Curitiba; seus trilhos, entretanto, não passaram de Juquiá. Em 1928, a ferrovia passou ao patrimônio do estado, recebendo a denominação atual e transformando-se num ramal da Estrada de Ferro Sorocabana (Paiva, 1993, p. 171).

$\mathrm{Na}$ época da inauguração da ferrovia, a Companhia Paulista de Terras e
Colonização começou a vender ou a arrendar terras por baixíssimo custo. Este fator atraiu imigrantes japoneses, principalmente okinawanos, que "tinham passado por amargas experiências na fazenda de café e/ou na estiva das docas de Santos" (Yamashiro, 1996, p. 49).

Ana Dias, Itariri, Alecrim (atual Pedro de Toledo), Pedro Barros, Miracatu, Biguá, Cedro e Juquiá, foram colônias formadas espontaneamente por imigrantes ao longo dessa ferrovia, em terras que adquiriram ou arrendaram da Companhia Paulista de Terras e Colonização. Nessa região, $77,2 \%$ da população era constituída de okinawanos e descendentes - de acordo com censo de 1950, citado por Yamashiro (1996, p. 231).

Inicialmente plantaram arroz, feijão e milho, depois partiram também para a horticultura, plantando vagem, tomate, alface, berinjela, pimentão, repolho, chuchu e tubérculos como a mandioca e batata doce; posteriormente, entraram no ramo de banana. Na década de 30 , a bananicultura superou as demais culturas, mas eles também se dedicaram à produção de carvão vegetal.

A produção de verduras e bananas era levada para os atacadistas e abastecia Santos e São Paulo. A capital tinha problemas de geadas no inverno, impedindo o cultivo de verduras e legumes.

"[...] muitos saíram da lavoura de café e vieram para o litoral, linha SantosJuquiá, porque o clima é semelhante a Okinawa, a característica geográfica lembrava bem a Ilha de Okinawa, verde de um lado e mar por perto, e a própria temperatura também igual de Okinawa, então a maior parte dos imigrantes okinawanos ficou nessa redondeza".4

A região tornou-se grande produtora de bananas ocorrendo uma expansão econômica e a conseqüente transformação das colônias em municípios. Em Itariri, foram incentivados pelo imigrante e antigo professor da colônia Seian Hanashiro, que se tornou um grande exportador do produto para a Argentina e para o Uruguai. Em Cedro, Riukiti Yasmashiro teve papel fundamental como uma das lideranças e representante da colônia junto aos governos brasileiro e japonês. Já em 1922, foi organizada a Associação de Japoneses da Linha Santos-Juquiá, dissolvida no final da década de 1920 . Lideranças locais, então, formaram associações de japoneses, independentes uma das outras.

O governo do Japão chegou a enviar verba tanto para assistência médica aos imigrantes, que sofriam doenças e epidemias de malária, tifo, difteria, cólera e até de bicho-de-pé, quanto para a construção de escolas nas colônias. Na linha Santos-Juquiá, escolas foram construídas em Itariri, Ana Dias e Cedro. As escolas ofereciam o ensino básico e cursos de japonês, além de tornarem-se centro da vida comunitária com reuniões, festas, competições esportivas denominadas 'undokai'.

A decadência da região Santos-Juquiá está ligada a fatores econômicos, sociais e culturais. Entre eles, a limitação natural devido à existência de morros e serras, impedindo a expansão do cultivo da banana, e o envelhecimento dos imigrantes que preferiram acompanhar seus filhos que se fixavam na capital e nas cidades do interior do estado.

\section{IMIGRANTES APÓS A SEGUNDA GUERRA MUNDIAL}

A entrada do Japão na Segunda Guerra Mundial fez surgir, em algumas famílias japonesas no Brasil, um sentimento de nacionalismo exacerbado a ponto de mandarem seus filhos para aquele país a fim de se tornarem soldados da pátria. Nas memórias de Jorge Seiken Hanashiro que, de 1939 a 1949 esteve em Okinawa com mais três irmãos pelo motivo citado, as lembranças dos preparativos dos japoneses para a guerra e da guerra. As comemorações que havia quando o Japão dominava uma cidade chinesa, marchinhas que incentivavam a formar o espírito de soldado e de guerra, como os alemães. Só conseguiu voltar, em 1949, através do Consulado da Suíça e porque 
tinha nacionalidade e passaporte brasileiros. Conta que trabalhou na base americana em Okinawa:

\section{"Eu servia a base americana como 'boy', acordava às 5 horas, entrava na cozinha e acendia fogão a querosene, só que com pressão [...] tinha que bombar pra poder levantar pressão, $e$ aí fazia café. Depois à tarde, fazia sorvete, exército americano já vinha preparado, até sorvete eles tinham. Fazia de manhã a panqueca e servia os soldados americanos e depois tinha que fazer faxina, lavar as panelas, os pratos...".5}

Diferentemente daqueles anteriormente citados, que tiveram a lavoura como destino, muitos imigrantes vindos após a Segunda Guerra Mundial tornaram-se feirantes montando barracas de frutas e legumes e de pastéis. Shinji Yonamine relata que se dedicaram também à costura, trabalhando para árabes e judeus:

\begin{abstract}
"[...] Com esse trabalho foi que o pessoal começou a comprar quitandas, abrir comércio de material de construção, enfim, partir para atividade mais rentável e junto a isso eles conseguiram também fazer com que os filhos pudessem ter uma formação universitária". ${ }^{6}$
\end{abstract}

\section{NA CIDADE DE SÃo PAULO}

A partir dos anos 50, alguns motivos trouxeram os okinawanos do interior para a capital paulista, entre eles: dificuldades econômicas; a utilização do veneno Rodiatox jogado no algodão, que causou a morte de vários imigrantes na região de Araçatuba; o medo de que a malária atingisse os filhos; o desejo de propiciar formação universitária aos filhos e, a ameaça que sofreram da Shindo Renmei. ${ }^{7}$ Sobretudo nos anos 1960 e 1970 , houve uma grande vinda de famílias japonesas para a cidade de São Paulo. Foram se agrupando em comunidades, seguindo a tradição, apoiando-se mutuamente. Segundo Kanashiro Yukihide ${ }^{8}$, "muitas dessas concentrações de famílias okinawanas deram origem às atuais subsedes". Nelas ensinavam as tradições e costumes aos jovens, e esses organizavam bailes, sessões de cinema, etc.

$\mathrm{Na}$ cidade de São Paulo, esses imigrantes montaram pequenos estabelecimentos comerciais como quitandas, bares, lojas de autopeças. Nas feiras livres predominaram à frente das barracas de legumes e verduras, mas, principalmente, nas de pastéis.

$\mathrm{Na}$ região central da cidade, às margens do rio Tamanduateí, o mercado da Cantareira tem a sua história marcada pela presença dos okinawanos. No final dos anos 50, segundo nossos informantes, os okinawanos constituíam $80 \%$ dos comerciantes desse mercado. Ali havia o comércio de varejo na parte de cima e, o atacadista, embaixo. Por causa de enchentes, na época do governo de Adhemar de Barros, o comércio atacadista foi transferido para o CEASA (Centro de Entreposto e Abastecimento S/A - atual CEAGESP). Os imigrantes da Cantareira mantinham - e alguns ainda mantêm - barracas de frutas e verduras, batata, cebola e alho.

Esses imigrantes acabaram fixando residência na região central da cidade nas proximidades do mercado Central. Esse local, além de concentrar um grande número de imigrantes, tornou-se referência dos okinawanos na capital. Mas, com o passar dos anos, houve uma mobilidade dos okinawanos na cidade de São Paulo, representando quase que uma divisão geográfica na cidade, de imigrantes de diferentes regiões de Okinawa.

\section{A VIDA CULTURAL E SOCIAL: SUAS ENTIDADES E ASSOCIAÇÕES}

Seus costumes e tradições são mantidos no âmbito familiar e social. A sociabilidade se revela pela existência das associações recreativas e culturais na cidade de São Paulo e no Brasil. A comunidade okinawana no Brasil hoje está organizada em 43 filiais (shibu), sendo 16 na Capital, 25 no interior de São Paulo e 3 em outros Estados. Envolvendo cerca de 4.000 famílias, os shibu se reportam à Associação Okinawa Kenjin do Brasil, na Capital paulista.

As subsedes contam com as Fujinkai (Associação de Senhoras), Sunenkai (Associação de Jovens), Seisonenkai (Associação de Jovens e Veteranos), Sonenkai (Associação de Veteranos), grupos de Minyo (música folclórica de Okinawa)) e de Koten (música clássica de Okinawa). Nas associações preservam a cultura: os mais velhos falam na sua própria língua, cantam, dançam e tocam shamisen (instrumento de três cordas e uma caixa revestida com couro de cobra) e o taiko (instrumento de percussão, ou tambor de vários tipos e tamanhos) e até o karaoque. Ali, realizam encontros, reuniões, chás beneficentes, assistem a apresentações artísticas. Enfim, as associações tornaram-se espaço do convívio, da sociabilidade e de lazer. Entre elas destacam-se a Associação Okinawa Kenji do Brasil (sede central) localizada na Rua Tomas de Lima e o Centro Cultural Okinawa do Brasil, construído em Diadema.

Nesse espaço funciona um clube de campo, um Museu Histórico de Okinawa, e atividades voltadas para a cultura de Okinawa como shows, danças, cantos populares, cursos. Realizam anualmente o Kyodo Matsuri de Okinawa (festival da cultura de Okinawa) com: danças folclóricas (Eissá), comidas típicas, cerimônia do chá (Buko Buko Chado) e o concurso de Miss Ryuso (Quimono típico de Okinawa) ${ }^{9}$. A vencedora representa o Brasil no Festival de Naha, em Okinawa, no mês de outubro.

\section{A RECONSTRUÇÃO DA IDENTIDADE ÉTNICA}

De meu contato com okinawanos, pude sentir que eles são mais abertos, espontâneos, alegres e simpáticos do que os de outras províncias japonesas (mais fechados, de frases curtas ou monossilábicas, mais contidos). Os okinawanos têm uma tradição cultural própria enraizada na religião, na dança e na música.

A música desempenhou um papel fundamental para o imigrante de Okinawa 


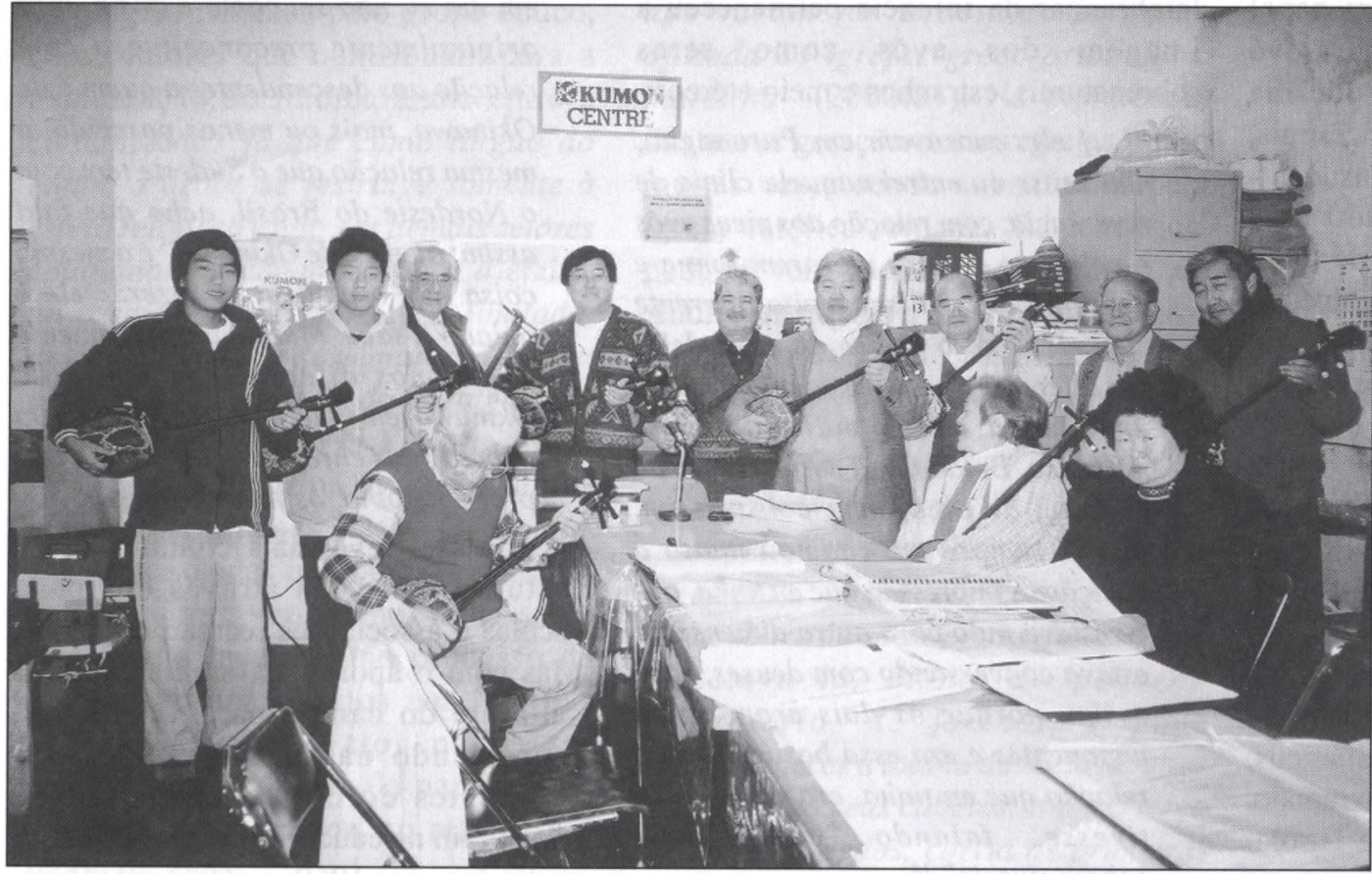

Grupo de Minyo (músicas folclóricas) do Shibu Jabaquara/São Paulo, 2001.
Foto: Sônia M. de Freitas

que atuavam nas associações, das quais elas não podiam participar. Elas fazem trabalho assistencial, reúnemse semanalmente para dançar e cantar. Numa dessas reuniões do Funjikai da sede percebi que elas tiveram seu comportamento (expressão facial, corporal, sorrisos) bastante alterado ao cantarem uma determinada canção. Ao conseguir uma tradução de "Ji dai no Nagare" (Tempo que corre), - canção bastante popular em Okinawa descobri que a letra versava sobre as mudanças de hábitos e costumes advindas da presença americana na Ilha. ${ }^{11}$ Segundo nos relataram alguns descendentes, ela trouxe uma transformação muito grande e

em São Paulo, tendo sido até mesmo tema de estudo (Satomi, 1998). Valores e costumes foram passados de pais para filhos, através de cantos populares, como a canção de tradição oral 'Thin sagu nu hana' ('A flor do beijo'), que fala da importância da família e dos valores transmitidos pelos pais, cantada por várias okinawanas durante depoimento à autora.

O shamisen (ou sanshin), que é instrumento de 3 cordas com caixa de ressonância feito em couro de cobra, veio na bagagem de muitos imigrantes de Okinawa - a província mais pobre do Japão. Nas colônias, reuniam-se para cantar e tocar o instrumento no Ano Novo, casamentos, aniversários, viagens de despedidas. Através da música - e também da religião - estabelecia-se um elo com a terra natal.

A música continua a fazer parte da vida dos Okinawanos e descendentes, tornando-se importante elemento definidor da identidade desse grupo étnico. No calendário de eventos da Associação do ano 2001, notei que não havia nenhuma festa cívica do tipo Dia de Okinawa, do Japão ou do Imperador e, sim uma série de eventos relacionados à dança e à música de Okinawa, além de campeonatos esportivos entre as subsedes. No geral, os filhos não falam o dialeto, falam o japonês, mas cantam diversas canções em okinawano. $\mathrm{Na}$ cidade de São Paulo há vários grupos de música espalhados pela cidade que se dedicam ao tipo Kotem, de tradição clássica e ao minyo, de tradição popular. A maioria dos descendentes preserva o minyo, como, por exemplo, os grupos da Vila Carrão, Jabaquara e Casa Verde, seja nas associações de jovens e das senhoras (Fujinkai), seja nos grupos próprios dessa modalidade.

O Grupo Minyo do shibu Jabaquara, por exemplo, conta com cerca de 15 pessoas: 13 nissei e 2 sansei. ${ }^{10}$ Entre eles, dois são professores (Tioiti Kochi e Paulo Oyakawa) que aprenderam a tocar com os seus avós, dos quais herdaram o instrumento. As canções são tristes, sentimentais e têm como temas: o amor, a moral, o costume, a honestidade, o trabalho e as dificuldades do camponês, a unidade familiar, o amor à pátria, a educação.

As senhoras formaram e participam dos Fujinkai e se reúnem nos diversos shibu. Em meados dos anos 60, os Fujinkai foram organizados pelas mulheres para dar suporte aos maridos isso está refletindo na cultura, principalmente na música.

\section{RELIGIÃO: O CULTO AOS ANCESTRAIS}

A religião é muito importante para os okinawanos e seus descendentes. Dos 50 informantes, a maioria declarou-se budista (25 pessoas), católica (12) e boa parte (9) não declarou a sua religião. Mas percebemos pelos depoimentos realizados que o culto aos ancestrais é ainda uma forte tradição desse grupo étnico. Nos lares, junto ao totome (butsudan), em um pequeno santuário, reverenciam seus ancestrais. Dentro dos totome se colocam pequenas placas de madeira nas quais são gravados os nomes de todos os antepassados. Nos dias primeiro e 15 de cada mês, os familiares oferecem doces e chá aos ancestrais, rezam pela saúde de todos e comunicam os principais acontecimentos.

Para o filho de imigrantes Shinji Yonamine, os okinawanos têm um costume familiar, espiritual que sobrepõe a religião porque ele está num conceito okinawano muito profundo, que é essa ligação, essa relação com a família na qual 
as mulheres desempenham um papel fundamental. Porque a mãe ou a avó okinawana ora pela família; todo dia acende um incenso, reza pelos ancestrais, troca a água e põe flores no Butsudan altar da família. Mas, segundo esse descendente, o okinawano faz de tudo: reza o Pai Nosso, vai ao Candomblé, ao centro espírita, ao Templo Budista ou Xintoísta, mas em casa, conserva-se a tradição. ${ }^{12}$

Relataram-nos alguns descendentes que alguns okinawanos têm, embora tenham negado no questionário e na entrevista, uma crença religiosa xamanista que teve influência do xintoísmo, do budismo e do taoísmo, do Japão e da China. Nesse xamanismo a Yuta, mulheres com poderes mediúnicos, são o meio de contato com o outro mundo. No depoimento da descendente Hiroko Teruya, que exerce a atividade de yuta na comunidade, percebe-se que houve no Brasil um sincretismo religioso, pois nota-se em seu ritual aspectos da religião católica e do candomblé:

"Na hora que eu nasci eu tenho certeza que fui recebida pela Nossa Senhora da Aparecida [...] mas sempre a Nossa Senhora da Aparecida falava: 'benze a pessoa que você cura'. [...] eu benzo através de vela, eu tenho água benta também, passa água benta [...]. Então a pinga veio do Japão, primeiro plantação do Okinawa, vem da batata e ofereceu pra Deus. Por isso que nós colocamos a pinga ao lado e tem muitas pessoas que não quer colocar pinga, entendeu? Então precisa colocar pinga agradecendo a Deus dos nossos antepassados. Agora temos ao lado sal, que nós recebemos da Deusa, Deusa Iemanjá, então essa parte veio do mar, então $85 \%$ nós precisamos de sal, né [...]". ${ }^{13}$

\section{A CONSCIÊNCIA ÉTNICA E O PRECONCEITO DOS JAPONESES}

O descendente de okinawano José Roberto Miney, relata que passou a se interessar pela culinária e pela cultura de Okinawa depois de adulto. Nas suas lembranças da infância permaneceu a imagem dos avós como seres sobrenaturais, estranhos e meio etéreos:

“[...] eles moravam em Paranaguá, não sei se eu entrei naquele clima de reverência, com relação aos meus avós $e$ pelo fato de eles morarem longe $e$ pelo fato de tudo ser muito diferente com eles, até o cheiro da casa deles era diferente do cheiro da minha casa, uma coisa assim marcadamente japonesa. Então tinha assim cheiro de incenso, de alga, uma coisa assim, aquilo sempre me chamou muito a atenção. A impressão que eu tinha, que eu estava indo para outra dimensão $e$ estava conversando com deuses, sabe assim, porque os dois eram muito imponentes e era essa basicamente a relação que eu tinha, era como se eu tivesse falando com seres sobrenaturais". ${ }^{14}$

Os okinawanos são considerados um mundo à parte pelos japoneses. Um descendente de okinawanos relatou-nos que os jornais japoneses publicam poucas matérias sobre eles. Talvez tenha sido este um dos motivos de terem criado o seu próprio jornal - Utiná Press: BrasilOkinawa, em 1998. E que, antigamente, japoneses de outras províncias não aceitavam casamentos de suas filhas com okinawanos.

José Roberto Miney narrou-nos de que maneira passou a ter consciência de que era descendente de okinawanos e do preconceito dos japoneses em relação aos okinawanos e a seus descendentes:

"A minha percepção é não acadêmica, de vivência [...] de quando eu morava em São Paulo ou em lugares onde havia uma comunidade japones a forte. Então, a primeira coisa que a pessoa dizia era: "você é descendente de Okinawa?", aí eu chegava para minha mãe e dizia assim: "Eu sou descendente de Okinawa? O que é que isso quer dizer?" Ela: "porque seus avós são de Okinawa e tudo". Posteriormente que eu comecei a entender um pouco melhor essa conotação, e da diferença, vamos dizer assim, que os japoneses fazem, acho que eles têm até uma certa visão, hoje em dia eu não sei como é que é, mas originalmente preconceituosa com relação aos descendentes a quem é de Okinawa, mais ou menos parecida, a mesma relação que o Sudeste tem com o Nordeste do Brasil, acho que fala assim: aí, ele é de Okinawa" é a mesma coisa que o paulistano dizer: "ele é baiano", sabe. Mesmo biotipicamente nós somos diferentes, quem é de Okinawa tem mais pelo, tem barba, tem cabelo mais enrolado, olho maior, tem prega no olho, os japoneses não". ${ }^{15}$

$\mathrm{O}$ nissei teve mais contato com a cultura okinawana através dos pais, escolas e associações recreativas rurais. Mas com o apoio das famílias, muitos saltaram do campo para as cidades, ingressando nas universidades. Os imigrantes do campo ou da cidade investiram na educação de seus filhos. A partir dos anos 1960, o nissei constituiuse numa parcela significativa da população universitária paulista. No ambiente universitário passaram a ter mais contato com a cultura brasileira, gerando algumas crises de identidade. É o que bem expressa o depoimento de Olga Futema:

“Há um momento, eu acho que no final
da infância, pré-adolescência que você
começa a descobrir que não é tão
bipolar como Brasil-Japão, que você
é algo que mais tarde vai saber que é
o terceiro elemento, que você carrega
em você ainda uma outra cultura, isso
numa cabeça pré-adolescente dá um
bom samba né. Você tem um
compromisso de ser mais brasileira
que você puder, por uma questão de
afirmação. Você não pode enfim
descartar porque é impossível a sua
cultura de origem e você tem ainda
uma outra cultura de referência, do
que é bom e do que é reconhecível por
essa sociedade brasileira, que no caso
era a cultura japonesa, isso é um
terreno pra crise sem dúvida, porque
só pra você ter uma idéia, na esfera
do comportamento isso nós estamos
aproximando da década de 60 , é uma
confusão muito grande, porque em
termos de comportamento de uma
menina, filha de okinawanos, mas que 
aos olhos brasileiros é japonesa, ela é cobrada em termos de ter um comportamento, na colônia, na comunidade okinawana é suposto dela ter ainda um outro comportamento mais fechado, mais agregado e com sonhos que caibam dentro daquela colônia, por exemplo casar-se com homem okinawano. E do ponto de vista da sociedade brasileira, num momento como aquele a gente tinha que, enfim, que despirocar completamente, $e$ de não ser exatamente uma pessoa normalzinha. Então eu acredito que sim, eu acho que, não eu, mas toda uma geração das pessoas que dispuseram a pensar sobre isso, eu acho que houve crise sim, não dramática, nenhum drama, mas assim de escolhas sabe, do que eu quero ser, ou melhor, como é que eu posso combinar todos esses modelos que são tão diferentes, eu acho que foi um momento assim de um enorme questionamento, né". ${ }^{16}$

Podemos considerar o depoimento de Olga como um testemunho de uma geração, percebemos como a questão da identidade se coloca para esses jovens da primeira geração de descendentes que chegaram às portas da universidade, e de que maneira ela é construída. Para Olga, descobrir que não era só bipolar, BrasilJapão e que carregava um terceiro elemento foi, sem dúvida, terreno para crise. Houve um questionamento, um dilema de como poderia combinar três modelos tão diferentes: ser brasileira por afirmação, não podendo descartar, porque impossível, a cultura de origem, e tendo ainda uma cultura de referência - a japonesa - reconhecível pela sociedade brasileira. Tudo isso somado a mudanças de comportamento ocorridas nos anos 60 no Brasil e no mundo.

\section{ESPÍRITO UCHINANCHU}

Os okinawanos criaram em São Paulo uma verdadeira rede de relações. Houve a concentração de pessoas da mesma região, cidade ou aldeia, nos mesmos bairros da capital. De acordo com Jorge Hanashiro, este espírito de união vem de Okinawa, das condições da natureza inóspita da ilha (clima semitropical com montanhas vulcânicas ao norte e recifes ao sul), dos tufões que passam pela ilha, nos meses de julho, agosto e setembro. Este forte sentimento de pertencimento ao grupo o ajudou a vencer as dificuldades na nova terra e a preservar a sua cultura Uchinanchu ${ }^{17}$.

Esse espírito Uchinanchu foi passado para os descendentes e, hoje, ele se reforça, em nível mundial, com a organização de encontros anuais promovidos pelo governo de Okinawa, com a participação de representantes de vários países.

* Sônia M. de Freitas é Doutora em História Social/USP e Coordenadora do setor de História Oral do Memorial do Imigrante/ Museu da Imigração da Secretaria da Cultura do Estado de São Paulo, Brasil.

\section{NOTAS}

1- Este texto é uma adaptação de um dos capítulos da tese de doutorado em História Social: Falam os imigrantes: memória e diversidade cultural em São Paulo, defendida na FFLCH/USP, em 2001.

2- Okinawa-ken, província japonesa, é um arquipélago situado no extremo sul do Japão, composto de 160 ilhas (Okinawa, Miyako, Yaeyama e adjacentes), das quais apenas 40 são habitadas. Estudos indicam que a etnia okinawana seja uma mistura de povos oriundos do Japão e Sudeste da Ásia, que ocuparam aquelas terras há cerca de $12 \mathrm{mil}$ anos (Yamashiro, 1997).

3- Em nossa pesquisa, a partir de contato estabelecido com a comunidade, através de suas associações e lideranças, foram realizadas 14 entrevistas com imigrantes e seus descendentes, bem como aplicados 50 questionários direcionados a okinawanos que delas participam.

4- Depoimento de Jorge Seiken Hanashiro à autora, em 31/8/1999, como diretor do Centro Cultural Brasil-Okinawa.

5- Idem.

6- Depoimento à autora, em 24/8/1999.

7- Sobre o tema ver Morais, 2000; o autor, utilizando fontes históricas, fez uma versão jornalística da história da Shindo Renmei.

8- Cf. 'O futuro da Associação Okinawa Kenjin do Brasil e seus setores'. In: Imigração okinawana no Brasil, p. 128.

9- Devido ao clima tropical, quente e úmido, os camponeses de Okinawa usavam quimonos feitos de fibra de bananeira (bassajin), por ser leve e refrescante. A classe nobre usava o bingata, feito de seda colorida, com estampas de flores.

10- A comunidade japonesa denominada de nikkei inclui o issei (imigrante), nissei (filho), sansei (neto), yonsei (bisneto), gosei (tataraneto).

11- De 1945 a 1972, Okinawa esteve sob o comando dos EUA, que ali ainda mantêm instalações militares e milhares de tropas. Alguns nissei se manifestaram contrários à presença americana na ilha.

12- Depoimento à autora, em 30/5/2001, como diretor da Associação Okinawa Kenji do Brasil. 13- Depoimento à autora, em 9/1999.

14- Depoimento à autora, em 30/9/1999 15- Idem

16- Depoimento à autora, em 1/9/1999.

17- Uchinanchu significa okinawanos no dialeto.

\section{REFERÊNCIAS BIBLIOGRÁFICAS}

FREITAS, Sônia Maria de

(2000) História Oral: possibilidades e procedimentos. São Paulo: HumanitasFFLCH/USP/ Imprensa Oficial.

ASSOCIAÇÃO Okinawa Kenjin do Brasil (2000) Imigração Okinawana no Brasil: 90 anos desde Kasato Maru. São Paulo, Associação Okinawa Kenjin do Brasil.

PREFEITURA de Okinawa

(1992) La cultura de Okinawa. Okinawa, Prefeitura de Okinawa.

MIYAGUI, Shosei

(1998) Okinawa: história, tradições e lendas. São Paulo, Oliveira Mendes.

MORAIS, Fernando

(2000) Corações Sujos. Companhia da Letras, São Paulo.

PAIVA, Odair da Cruz

(2002) Colonização e (des)povoamento: intervenção governamental e reordenação fundiária no Litoral Sul e Vale do Ribeira de Iguape nos anos 1930/40. São Paulo, Edições Pulsar.

SATOMI, Alice Luni

(1998) As gotas de chuva no telhado: música de Ryukyu em São Paulo. Salvador: Universidade Federal da Bahia, 1998. (Tese de Mestrado em Música-Etnomusicologia).

UCHIYAMA, Katsuo et alli

(1991) "Emigração como política de Estado". In: Uma epopéia moderna: 80 anos da imigração japonesa no Brasil. São Paulo, Editora Hucitec/Sociedade Brasileira de Cultura Japonesa.

YAMASHIRO, José

(1996) Trajetória de duas vidas: uma história de imigração e integração. São Paulo, Aliança Cultural Brasil-Japão/Centro de Estudos Nipônicos-Brasileiros.

YAMASHIRO, José

(1997) Okinawa: uma ponte para o mundo. São Paulo, Cultura. 